\title{
Numerical Investigation of Hydrodynamics Induced by a Pitched Blade Turbine: Effect of the Shape of Vessel Base
}

\author{
Abdelghani BELHANAFI*, Mohamed BOUZIT** \\ *Université des sciences et de la technologie USTO-MB, 1505 El M'nouar, 31000 Oran, Algérie, Faculté de Génie Méca- \\ nique, Laboratoire des sciences \& ingénieries maritimes, E-mail: abdelghani.belhanafi@univ-usto.dz \\ **Université des sciences et de la technologie USTO-MB, 1505 El M'nouar, Oran, Algérie, Faculté de Génie Mécanique, \\ Laboratoire des sciences \& ingénieries maritimes, E-mail: bouzit_mohamed@yahoo.fr \\ crossref http://dx.doi.org/10.5755/j01.mech.25.5.23015
}

\section{Introduction}

The agitation-mixing is a very common operation in the industry process (chemicals, food, pharmaceuticals, etc.) used to obtain close contact between two phases, to get a reaction or promote mass or heat transfer. The detailed knowledge of hydrodynamic structures of turbulent flows in these systems allows to understand the transport phenomena. It also improves the performance of mobile agitation implemented by the development of optimal geometric and operating conditions for simultaneously improving the quality of the mixture and saving energy. Numerical simulations are conducted by Hao et al. [1] to investigate the effect of bottom shape on the hydrodynamics and particle suspension in a DTB crystallizer. Ameur [2] carried out an interesting study on the effects of the impeller clearance from the tank bottom by realizing three types of configurations: a flat bottomed cylindrical vessel, a dished bottomed cylindrical vessel and a spherical vessel. He concluded then that the tank with spherical shape provides uniform flows in the whole vessel volume and it requires less energy consumption. Different geometries of tank were analyzed, by varying impeller distance from vessel bottom using three types of impeller (Rushton turbine, Lightnin A310, Pitched Blade Turbine) experimentally study by Busciglio et al. [3]. For each investigated geometry, the deformed free-surface was analyzed at different impeller speeds. From instabilities on the dynamic flow Pieralisi et al. [4] investigated by Particle Image Velocimetry (PIV) in two cylindrical stirred tanks with different dimensions, named T49 and T23. In the first case T49, three different liquid heights were employed, $\left(H_{L}=0.69 H ; 0.78 H\right.$ and $0.92 H$, respectively) and for the second case T23, two different liquid heights were employed, $\left(H_{L}\right.$ $=0.71 H$ and $0.83 H)$. Comparative study by Yang et al. [5] was made, on the influences of 10 different water tank shapes on thermal energy storage capacity and thermal stratification in the static mode operation under laminar natural convection. Using PIV, Rodriguez et al. [6] investigated in the flat bottom tank with the objective to evaluate the effects of conical shaped bottoms of different height on the fluid flow, configuration $\mathrm{A}$ (cone height, $h_{\text {cone }}=5 \mathrm{~mm}$; angle from the horizontal, $\left.\alpha_{\text {cone }}=6.3^{\circ}\right)$ and configuration B $\left(h_{\text {cone }}=15 \mathrm{~mm} ; \alpha_{\text {cone }}=18.4^{\circ}\right)$. They found that the flow in cylindrical bioreactors with conical bottoms is characterized by toroidal vortices expanding towards the bottom with increasing Froude number ( $\mathrm{Fr}$ ), as is the case for a standard flat configuration, while for the cone with the highest inclination examined (conical B) the vortices reaching the bottom at a lower Fr. Numerical and experimental studies carried out by Antonija et al. [7] simulate the mobile type effect of agitation and its position in a cooling catalyst on increasing kinetic crystal borax decahydrate. The geometry used is a cylindrical flat bottom tank equipped with four baffles placed at $90^{\circ}$ with a distance ratio between the impeller and the bottom varies from 0.1 to 0.5 for three types of turbines and four different blades (blade turbine SBT right, pitched blade turbine PBT and A310 hydrofoil impeller). The parametric analysis was treated by Ayranci et al. [8] on the hypothesis that at complete off-bottom suspension is a critical flow condition that exists close to the bottom of the tank at every clearance for fixed solids, tank geometry and constant circulation pattern, using visual observations of the tank bottom employing PIV and LES devices. The experimental study performed by Ghionzoli et al. [9] in a baffled vessel stirred with a $45^{\circ}$ pitched blade turbine, to evaluate the influence of the bottom roughness on particle suspension. A comparative study conducted by Jie et al. [10] on the bottom shape and the baffles length in two agitated tanks, flat bottom and dished bottom equipped with a Rushton turbine on the distribution of velocity in transitional and turbulent flow. The effect of eccentrically located position of impeller on mixing time was investigated by Koji et al. [11] in agitated vessels of different bottom shapes. An experimental and theoretical studies were made by Bruha et al. [12] on the dynamic flow patterns and their influence on the liquid surface in a cylindrical stirred tank flat-filled water equipped with a 6-blade impeller inclined $45^{\circ}$ to the bottom pumping. LDV method was used by Aubin et al. [13] to measure one phase turbulent flow regime in a baffle-bottomed tank with two different mobile PBT6 agitation and axial MTT6 operational in two high-beats pumping modes. By changing the pumping direction in the low mode, they observed the formation of two loops of circulation, a lower and upper second turbine with a good high pumping achieved a value of $22.5 \%$ (PBT) and $13.7 \%$ (MTT). Aubin et al. [14] studied numerically the influence of the pumping direction for a turbine to six inclined blades. They concluded that the number of power and the pumping number is greater in one direction than in the other. Zied et al. [15] used a specific code CFD for numerical analysis in order to study the influence of inclination angles $\beta$ of blades $45^{\circ}, 60^{\circ}$ and $75^{\circ}$ on the distribution of fields velocity and characteristic of turbulence in a stirred vessel equipped with 6 blades.

The present work aims to determine the influence of geometrical parameter of a stirred vessel with down pumping direction from a pitched blade turbine (PBT $45^{\circ}$ ) 
on the hydrodynamic flow structure. The effect of the addition of a cylindrical bump in the center of dished bottom tank and the reduction of the bottom height with the same distance by realizing four geometries are also investigated.

\section{Geometry configurations}

In this paper four geometrically scaled vessels are chosen in Fig. 1 with different tank height: $H_{1}=0.190 \mathrm{~m}$, $H_{2}=0.177 \mathrm{~m}, H_{3}=0.164 \mathrm{~m}$ and $H_{4}=0.152 \mathrm{~m}$. The first system configuration case 1 is similar to Aubin et al. application (2004). Tank height is the same to the diameter $H=T$ for each system, and completely filled with water. In each case, the six pitched blades turbine $\mathrm{PBT} 45^{\circ}$ with diameter $D_{1}=H_{1} / 2, D_{2}=H_{2} / 2, D_{3}=H_{3} / 2$ and $D_{4}=H_{4} / 2$, respectively located at an off-bottom clearance $C_{1}=H_{1} / 3, C_{2}=H_{2} / 3$, $C_{3}=H_{3} / 3$ and $C_{4}=H_{4} / 3$. The distance $F$ between the bottom tank and the bump top is $0.010 \mathrm{~m}$ and the Reynolds numbers from 45000 were diameter $E=D / 4$. investigated.

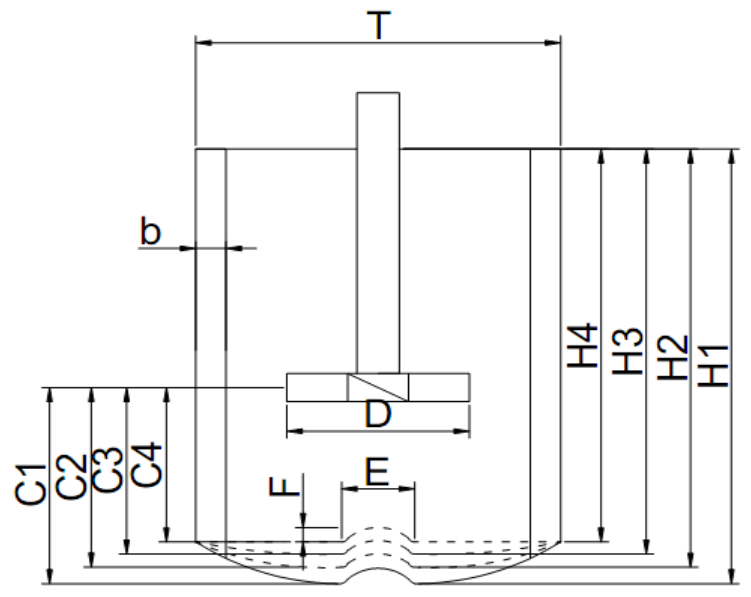

Fig. 1 Mixing vessel dimensions

Geometrical configuration parameters

Table 1

\begin{tabular}{|c|c|c|c|c|}
\hline Cases & Tank diameter $(\mathrm{m})$ & Impeller diameter $(\mathrm{m})$ & Clearance $(\mathrm{m})$ & Vessel type \\
\hline Case 1 & $H_{1}=0.190$ & $D_{1}=0.095$ & $C_{1}=0.063$ & Dished bottom \\
\hline Case 2 & $H_{2}=0.177$ & $D_{2}=0.088$ & $C_{2}=0.059$ & Dished bottom \\
\hline Case 3 & $H_{3}=0.164$ & $D_{3}=0.082$ & $C_{3}=0.054$ & Dished bottom \\
\hline Case 4 & $H_{4}=0.152$ & $D_{4}=0.076$ & $C_{4}=0.050$ & Flat bottom \\
\hline
\end{tabular}

\section{Numerical procedure}

In this work the pre-processor (ICEM CFD) was used to discretize the 3D flow domain with a tetrahedral mesh Fig. 2. Increased mesh density was used near the impeller and tank walls to capture the flow details at the boundary layer. A large number of nodes defining the curvature of the blades was created on the edge of the impeller which result in very refined mesh in this area. The domain is divided into two distinct zones. A rotating zone (Fig. 2, b) that describes the rotational motion of the fluid around the impeller, this zone is discretize with 188773 nodes. Tank walls and baffles constitutes the stationery zone (Fig. 2, a) by 530208 nodes.

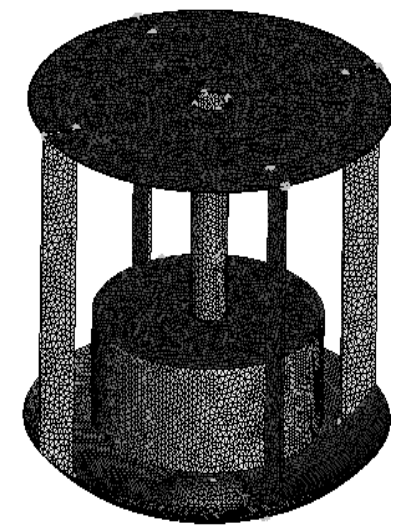

a) Stationery zone

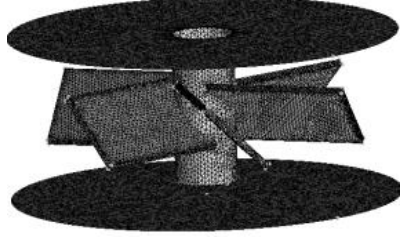

b) Rotating zone
Fig. 2 Tetrahedral mesh generation

The boundary conditions are introduced in code ANSYS CFX-Pre, using the multiple referential approach (MRF). In this approach, the flow fields are connected at the interior surfaces (interface) separating the two domains by the method called frozen rotor. The simulation is calculated on a Pentium (R) Core i7 with 8.0 GB of RAM.

\section{Mathematical formulation}

\subsection{Governing equations}

The flow in a stirred vessel can be solved with the equations that describe the Navier-Stokes conservation matter and the of amount of movement. Moreover, the equations are written in their averaged form RANS (Reynolds Averaged Navier Stokes) used in the case of a turbulent flow, due to the time of the turbulence scales being very weak.

The conservation of matter gives:

$$
\frac{\partial \rho}{\partial t} \Delta \cdot(\partial t)=0
$$

where: $\rho$ is the density, $t$ is the time and $u$ velocity.

Conservation of momentum:

$$
\frac{\partial \rho}{\partial t}+\Delta \cdot(\rho u \otimes u)+\Delta \cdot\left(\tau+-\rho \overline{u^{\prime} \otimes u^{\prime}}\right)-\rho g=0,
$$

where: $\tau$ is the shear stress and is given by:

$$
\tau=-p \delta+\mu\left(\Delta u+(\Delta u)^{T}\right)
$$

for a Newtonian fluid, the term $\left(-\rho \overline{u^{\prime} \otimes u^{\prime}}\right)$ called Reynolds stress, is the product of velocity fluctuations, and it appears when the equations are averaged. It represents the transport of momentum by the turbulence, and it must be modeled to solve the equations. 

fellow:

For each species, the form equation can write as

$$
\frac{\partial \rho c}{\partial t}+\Delta \cdot(\rho u c)=\Delta \cdot\left(D \Delta c-\rho \overline{c^{\prime} u^{\prime}}\right)+R
$$

where: $C$ is the species concentration, $D$ is laminar diffusion coefficient and $R$ is represents the terms due to reactions.

\subsection{Turbulent modeling}

\subsection{1. $K-\varepsilon$ model}

This model which dates from 1970, is based on the following two equations representing the conservation of the turbulent kinetic energy $k$ and the dissipation rate of the turbulent kinetic energy $\varepsilon$ respectively:

$$
\begin{aligned}
& \frac{\partial \rho k}{\partial t}+\Delta \cdot(\rho u k)=\Delta \cdot\left(\left[\mu+\frac{\mu_{t}}{\sigma k}\right] \Delta k\right)=P-\rho \varepsilon, \\
& \frac{\partial \rho \varepsilon}{\partial t}+\Delta \cdot(\rho u \varepsilon)=\Delta \cdot\left(\left[\mu+\frac{\mu_{t}}{\sigma \varepsilon}\right] \Delta \varepsilon\right)= \\
& =C_{1} \frac{\varepsilon}{k} P-C_{2} \frac{\varepsilon^{2}}{k} .
\end{aligned}
$$

In the above equations, the quantity $P$ is the production of kinetic energy, which is calculated from:

$$
\begin{aligned}
& P=\mu_{e f f} \Delta u \cdot\left(\Delta u+(\Delta u)^{T}\right), \\
& \mu_{e f f}=\mu+\mu_{t}=\mu+C_{\mu} \rho \frac{k^{2}}{\varepsilon} .
\end{aligned}
$$

where: $\mu_{\text {eff }}$ is the effective viscosity and $\mu_{t}$ is the turbulent viscosity. Eqs. (6) and (7) are based on exact equations but reveal required constants to model the turbulence. The "standard" constant values are:

$$
C_{\mu}=0.09, C_{1}=1.44, C_{2}=1.92, \sigma_{k}=1.0, \sigma_{\varepsilon}=1.3 \text {. }
$$

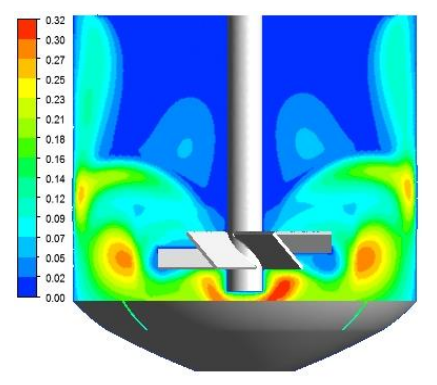

a- case 1

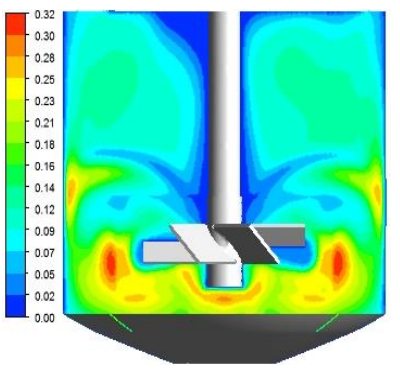

b-case 2

\section{Numerical results}

\subsection{Comparison with experimental results}

Fig. 3 shows the radial profile of dimensionless turbulent kinetic energy in axial position $z / H=0.11$ at downpumping in the stirred vessel equipped with pitched-blade turbine a $45^{\circ}$ PBT6. The comparison between the numerical results and the experimental results found by Aubin et al. [14] shows good agreement, which proves the validity of the adopted numerical method.

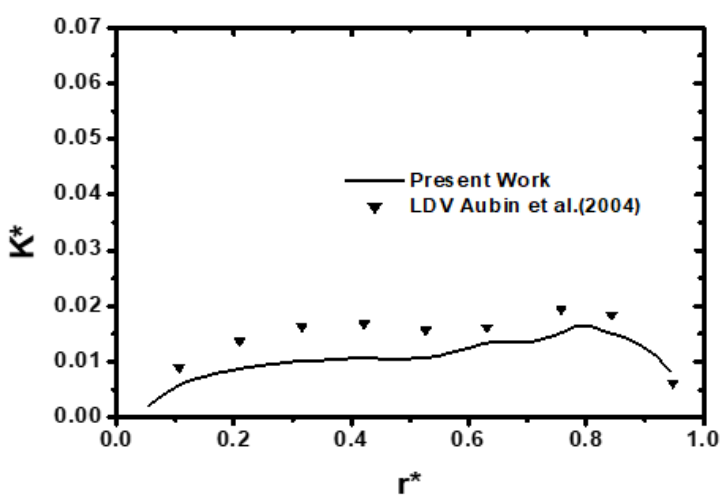

Fig. 3 Radial profiles of dimensionless turbulent kinetic energy for $N=300 \mathrm{rpm}, z / H=0.11 \mathrm{Dp}$

\subsection{Results and discussion}

\subsubsection{Turbulent viscosity distribution}

Fig.4 represents the turbulent viscosity distribution in the vertical plan for four configurations. From these results, it is found that the seat of the maximum values of turbulent viscosity region is located at the tips of the blades. The closer bump to the turbine intensifies the displacement of the turbulent viscosity towards the tank solid walls. Also it is noted that for both configurations tank with dished bottom case 2 and case 3 (Fig. 4, b and 4, c), the wake of the turbulent viscosity grows at the upper part of the tank compared to the other two configurations case 1 and case 4 (Fig. 4, a and 4, d). More the distance turbine-bump becomes large or close, the turbulent viscosity in the upper part of tank becomes weaker. Maximal values are obtained from case 1 tank with flat bottom (Fig. 4, d).

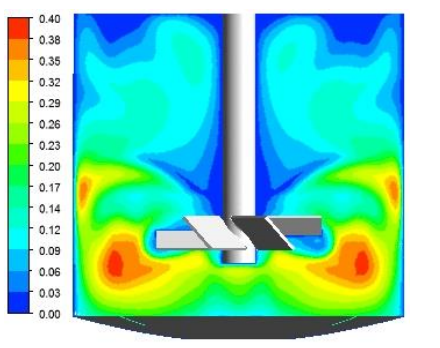

c-case 3

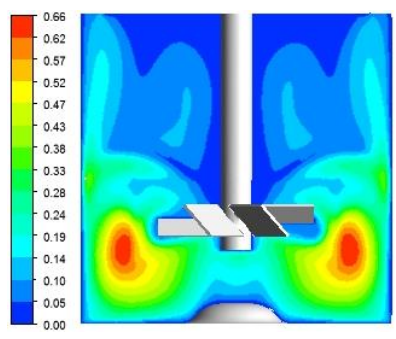

d- case 4

Fig. 4 Turbulent viscosity contours in vertical plane for different configurations (Table 1)

\subsubsection{Turbulent kinetic energy distribution}

The turbulent kinetic energy distribution is shown in Fig. 5 on the vertical plane respectively. The turbulent kinetic energy keeps a high value at the proximity side wall of the tank for the $3 \mathrm{rd}$ and 4 th configurations case 3 and case 4 (Fig. 5, c and 5, d). These results show that the volume swept by the turbine and the change action of the trajectory 
jet caused by the bump. In the first configuration case 1 tank with dished bottom (Fig. 5, a), the turbulent kinetic energy

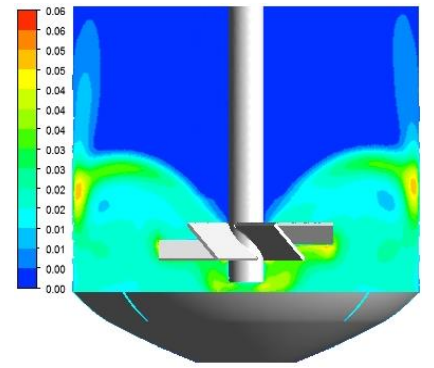

a- case 1

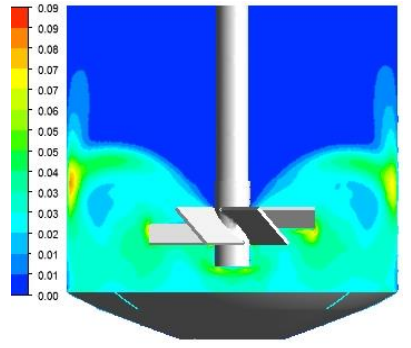

b-case 2

is very low with $0.06 \mathrm{~m}^{2} / \mathrm{s}^{2}$ compared to the other configurations.

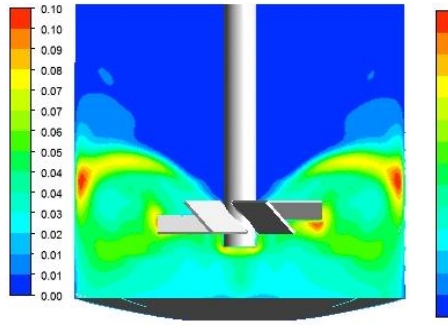

c-case 3

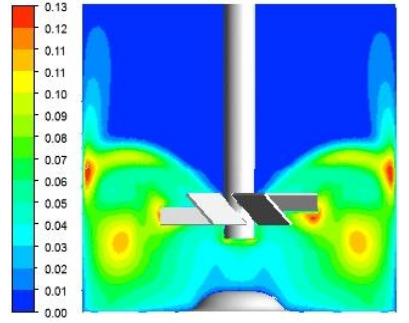

d- case 4

Fig. 4 Turbulent kinetic energy in vertical plane for different configurations (Table 1)

\subsubsection{Radial profiles of turbulent kinetic energy}

The profiles plotted on Fig. 6 give the distribution of turbulent kinetic energy dimensionless for four cases at different axial positions from vessel base $z=5,10$ and $15 \mathrm{~mm}$ for each configuration. Starting from $z=10 \mathrm{~mm}$ at the top of bump it can be see that turbulent kinetic energy increases with improvement for geometrical configuration named case 3 (Fig. 6, b). In the both configurations tank with dished bottom case 1 and case 2, the turbulent viscosity is very low compared to the other configurations case 3 and case 4 as the position of $z$ changes from $5 \mathrm{~mm}$ (mid-bump) to $15 \mathrm{~mm}$. Also it is noted that the optimal values of $K *$ is extended in the case 4 tank with flat bottom. As the height of the rounded bottom becomes important with the presence of the bump, the turbulent kinetic energy decreases.

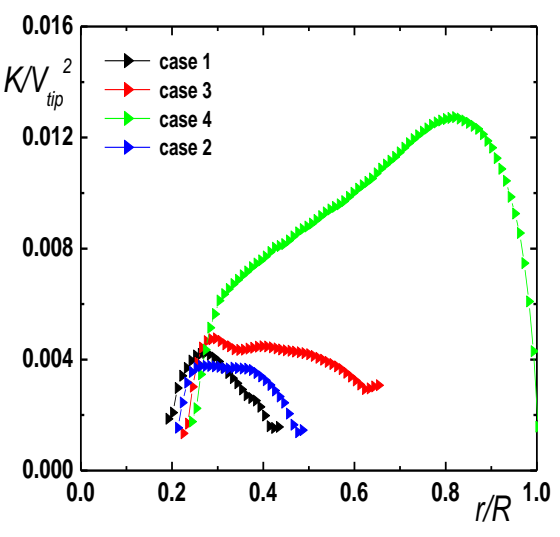

a

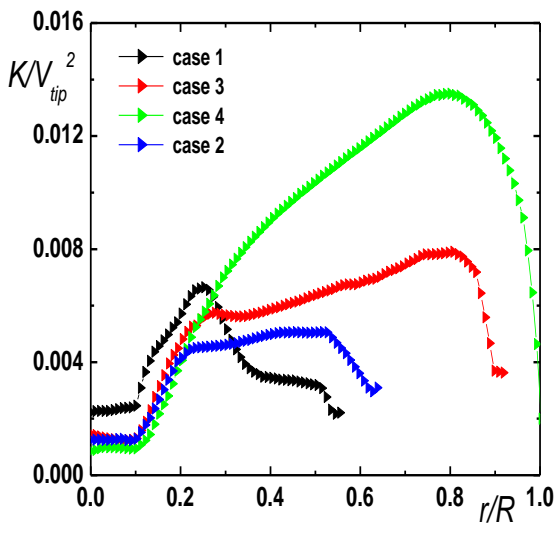

$\mathrm{b}$

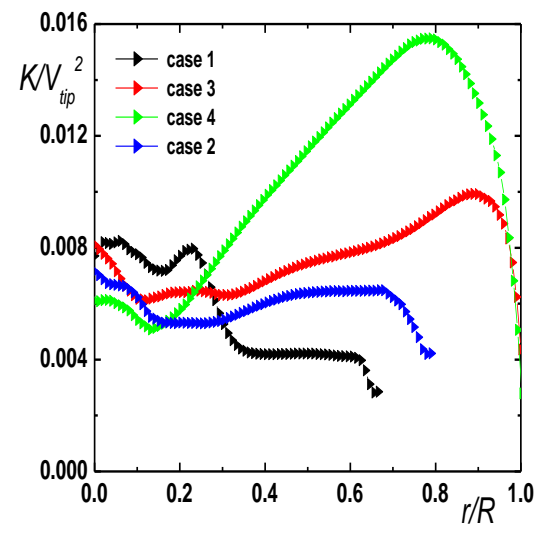

$\mathrm{c}$

Fig. 6 Radial profiles of the turbulent kinetic energy for different positions a) $z=5 \mathrm{~mm}, \mathrm{~b}) z=10 \mathrm{~mm}, \mathrm{c}) z=15 \mathrm{~mm}$

\subsubsection{Mean velocity distribution}

The vertical presentation planes of average velocity distribution illustrated in Fig. 7 for four geometries. Globally, in the domain swept by the turbine blades, the velocity remains enough elevated. For each configuration the

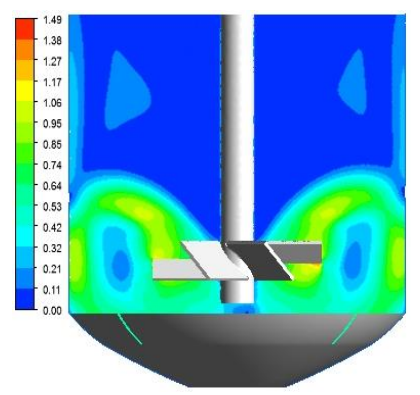

a- case 1

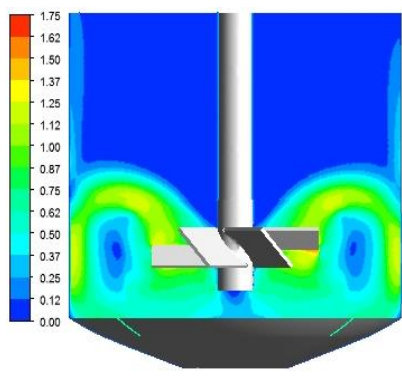

b-case 2

development of a circulating movement, with the intensity varies according to the bottom shape effect. In case 4 vessel with flat bottom shape (Fig. 7, d), the velocity obtained optimal value of $2.15 \mathrm{~m} / \mathrm{s}$.

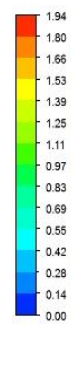

c-case 3

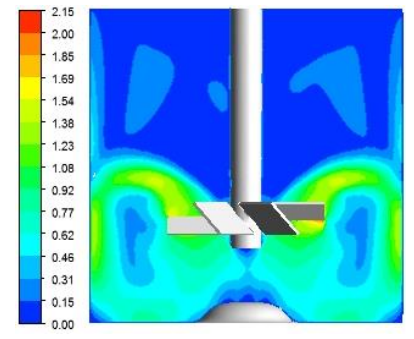

d- case 4

Fig. 5 Mean velocity in vertical plane for different configurations (Table 1) 


\subsubsection{Flow patterns in $r-z$ plan}

The velocity vectors flow generated for all configuration studies are shown in Fig. 8. These figures indicate the dominance of a radial jet originating from the turbines and divide in two jets when it reaches the side wall of the tank. The descending jet creates an intense recirculation

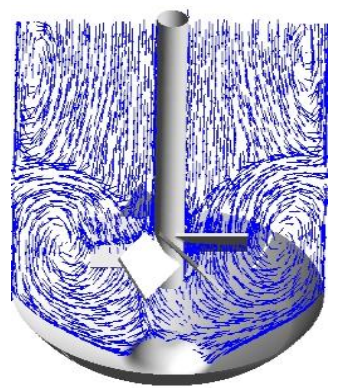

a- case 1

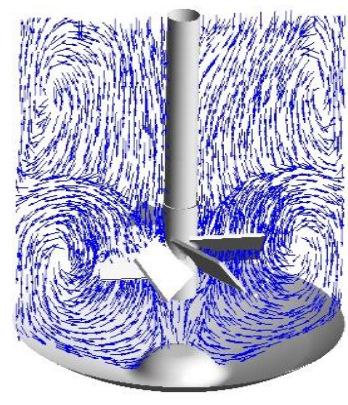

b-case 2

zone at the bottom, whilst the ascending jet decreases gradually on the configurations case 1, case 2 and case 4 (Fig. 8, $\mathrm{a}, \mathrm{b}$ and d). But a very larger circulation loops are formed below the impeller near the vertical solid wall of tank in case 3 with a dished bottom (Fig. 8, c). This explains by the reduction of bottom height and shape of vessel base for each configuration.

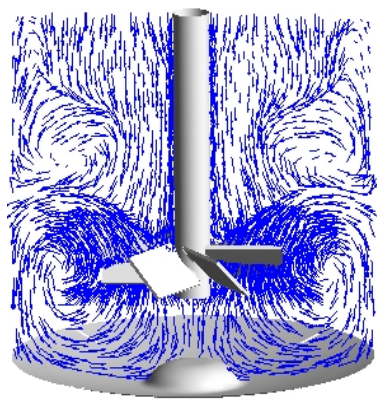

c-case 3

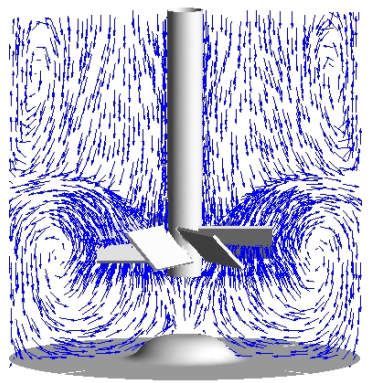

d- case 4

Fig. 8 Flow patterns in vertical plane for different configuration (Table 1)

\subsubsection{Tangential velocity}

The tangential velocity dimensionless is plotted in Fig. 9 for the four cases studied with different axial levels at the bottom tank $z=5,10$ and $15 \mathrm{~mm}$. Globally, we note a great similarity between these profiles. At mid-bump $z$ $=5 \mathrm{~mm}$ the velocity optimum values obtained for case 4 tank with flat bottom shape at +0.25 and -0.35 corresponding to $r^{*}=0.28$ (Fig. 9, a) and $r *=0.95$. Fig. 9, b and c clearly indicates maximum values of tangential velocity magnitude for two positions $z=10 \mathrm{~mm}$ and $z=15 \mathrm{~mm}$ with range $0.1<r *<0$ from all configurations. The bottom shape and length of the baffles forced the recirculation loops from tangential velocity with negatives values.

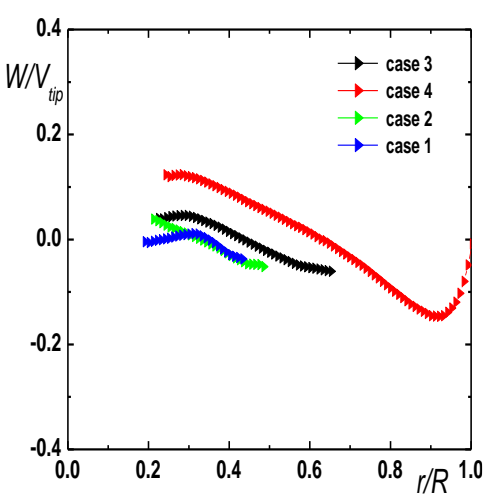

a

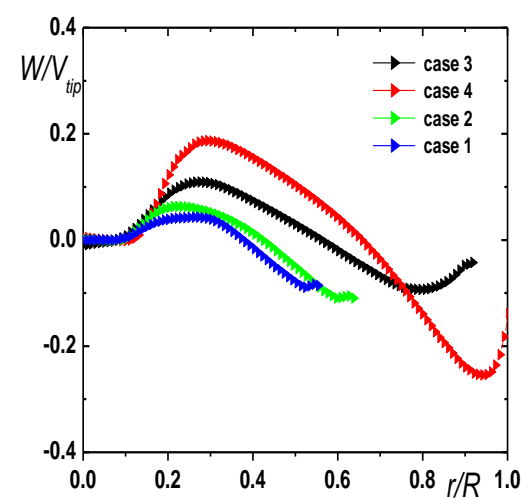

b

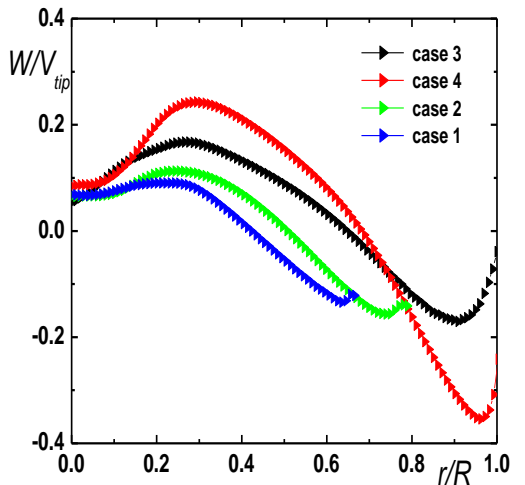

C

Fig. 9 Tangential velocity for different positions a) $z=5 \mathrm{~mm}, \mathrm{~b}) z=10 \mathrm{~mm}, \mathrm{c}) z=15 \mathrm{~mm}$

\subsubsection{Radial velocity}

The radial velocity profile dimensionless observed in the vessel base (Fig. 10). At mid-bump $z=5 \mathrm{~mm}$, the profiles for the four curves are distributed with decreasing manner for case 1 , case 2 , case 3 and case 4 (Fig. 10, a). The radial velocity distribution is reversed and became case 4 , case 3, case 1 and case 2 (Fig. 10, c) as the axial position change from $z=5 \mathrm{~mm}$ to $z=15 \mathrm{~mm}$ caused by the reduction of the distance between bump and the turbine. The negative velocity values indicate a recirculation zone in the range $0.2<r *<1$.

\section{Conclusions}

The investigation in this work was to determine the effect of an approaching bump at the turbine with different geometries. From the presented results the following conclusions can be deduced:

In planes $r-z$ the effect from the reduction on the bottom height for all configurations tank with bump allows good growth parameters mixture for turbulent viscosity, turbulent kinetic energy and mean velocity.

The closer bump to the turbine causes an intensive movement of the turbulent viscosity toward the tanks solid walls and a good improvement on the upper part for both configurations case 2 and case 3 . It minimizes the stagnation of the turbulent kinetic energy at the bottom tanks.

The values of the velocity components and turbulent kinetic energy dimensionless are less elevated near the bottom at mid-bump $z=5 \mathrm{~mm}$. This is due to the reduction of the passage section from the fluid at the vessel base. As the position changes from $z=10$ to $z=15 \mathrm{~mm}$, the acceleration of the velocity dimensionless, causes by the absence of obstacle trajectory flow. 


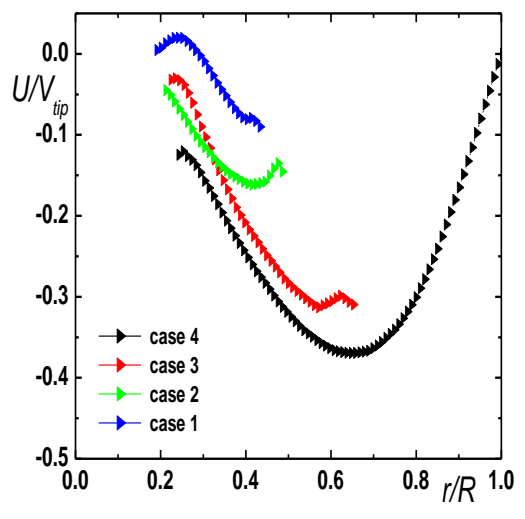

a

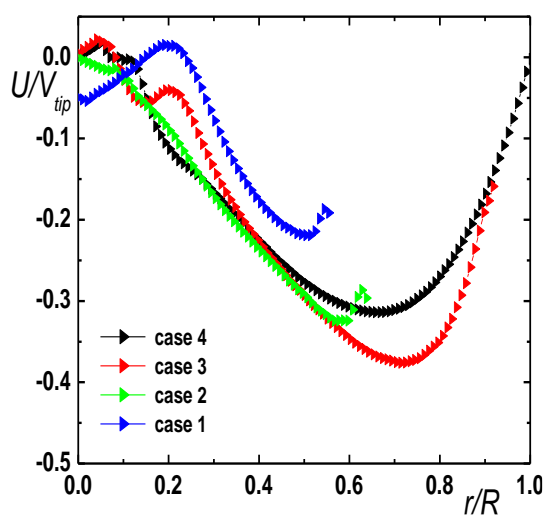

b

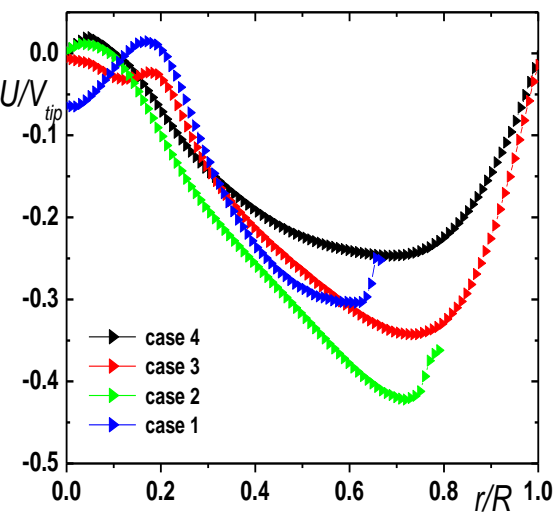

$\mathrm{c}$

Fig. 10 Radial velocity for different positions a) $z=5 \mathrm{~mm}, \mathrm{~b}) z=10 \mathrm{~mm}$, c) $z=15 \mathrm{~mm}$

\section{References}

1. Hao, P.; Jun, L.; Yang, J.; Bo, Y.; Xing, L. 2016. Numerical investigation of the effect of bottom shape on the flow field and particle suspension in a DTB crystallizer, International Journal of Chemical Engineering 11: 6862152.

http://dx.doi.org/10.1155/2016/6862152.

2. Ameur, H. 2016. Agitation of yield stress fluids in different vessel shapes, Engineering Science and Technology, an International Journal 19: 189-196.

http://dx.doi.org/ 10.1016/j.jestch.2015.06.007.

3. Haque, J. N.; Mahmud, T.; Roberts, J. K.. Liang, G., White, G., Wilkinson, D., Rhodes, D. 2011. Free-surface turbulent flow induced by a Rushton turbine in an unbaffled dish-bottom stirred tank reactor: LDV measurements and CFD simulations, The Canadian Journal of Chemical Engineering 89(4): 745-753.

https://doi.org/10.1002/cjce.20599.

4. Pieralisi, I.; Montante, G.; Paglianti, A. 2016. Prediction of fluid dynamic instabilities of low liquid heightto-tank diameter ratio stirred tanks, Chemical Engineering Journal 295: 336-346.

http://dx.doi. org/10.1016/j. cej.2016.03.026.

5. Yang, Z.; Chen, H.; Wang, L.; Sheng, Y.; Wang, Y. 2016. Comparative study of the influences of different water tank shapes on thermal energy storage capacity and thermal stratification, Renewable Energy 85:31-44. http://dx.doi. org/10.1016/j.renene.2015.06.016.

6. Rodriguez, G.; Pieralisi, I.; Anderlei, T.; Ducci, A.; Micheletti, A. 2016. Appraisal of fluid flow in a shaken bioreactor with conical bottom at different operating conditions, Chemical Engineering Research and Design 108: 186-197.

http://dx.doi. org/10.1016/j.cherd.2015.12.012.

7. Antonija, K.; Akrap, M.; Kuzmanic, N. 2013. Effect of impeller type and position in a batch cooling crystallizer on the growth of borax decahydrate crystals, Chemical Engineering Research and Design 91: 274-285. http://dx.doi. org/10.1016/j. cherd.2012.07.010.

8. Inci, A.; Marcio, B.M.; Adam, M.M.; Jos, J.D. 2012. Effect of geometry on the mechanisms for off-bottom solids suspension in a stirred tank, Chemical Engineering Science 49:163-176.

http://dx.doi. org/10.1016/j.ces.2012.05.028.
9. Ghionzoli, A.; Bujalski, W.; Grenville, R. K.; Nienow, A. W.; Sharpe, R. W.; Paglianti, A. 2007. The effect of bottom roughness on the minimum agitator speed required to just fully suspend particles in stirred vessel, Trans IChemE, Part A, Chemical Engineering Research and Design 49: 163-176. http://dx.doi. 10.1205/cherd06152.

10. Jie, D.; Binjie, H.; Andrzej, W. P.; Xiaogang, Y.; Nicholas, J. M. 2016. The Effect of bottom shape and baffle length on the flow field in stirred tanks in turbulent and transitional flow, International Journal of Mechanical 10(9): 10005417.

11. Koji, T.; Shigihara, D.; Yasuyuki, T. 2011. Laminar mixing in eccentric stirred tank with different bottom, Journal of Chemical Engineering of Japan 44(2): 931935 . http:// dx.doi.10.1252/jcej.11we109.

12. Bruha, T.; Jahoda, M.; Fort, I. 2011. Dynamics of flow macro-formation and its interference with liquid surface in mixing vessel with pitched blade impeller, Chemical Engineering Research and design 89: 22792290. http://dx.doi. org/10.1016/j.cherd.2011.04.019.

13. Aubin, J.; Mavros, P. D.; Fletcher, F.; Bertrand, J.; Xuereb, C. 2001. Effect of axial agitator configuration (up-pumping, down-pumping, reverse rotation) on flow patterns generated in Stirred Vessels, Trans IChemE 79: 845-56.

14. Aubin, J.; Fletcher, D. F.; Xuereb, C. 2004. Modeling turbulent flow in stirred tanks with CFD: the influence of the modeling approach, turbulence model and numerical scheme, Experimental Thermal and Fluid Science 28: 431-445. http://dx.doi. 10.1016/j.expthermflusci.2003.04.001.

15. Driss, Z.; Bouzgarrou, G.; Chtourou, W.; Kchaou, H.; Abid, M. S. 2011. Computational studies of the pitched blade turbines design effect on the stirred tank flow characteristics, European Journal of Mechanics B/Fluids 29: 236-245.

http://dx.doi. 10.1016/j.euromechflu.2010.01.006.

16. Kamla, Y.; Bouzit, M.; Hadjeb, A.; Arab, I. M. Beloudane, M. 2016. CFD study of the effect of baffles on the energy consumption and the flow structure in a vessel stirred by a Rushton turbine, Mechanika 22(3): 190-197. http://dx.doi.org/10.5755/j01.mech.22.3.12663. 
17. Ameur, H.; Bouzit, M. 2013. 3D hydrodynamics and shear rates' variability in the united states pharmacopeia paddle dissolution, International Journal of pharmaceutics 42: 42-51.

http://dx.doi.org/ 10.1016/j.ijpharm.2013.04.049.

18. Pianko, O. P.; Nienow, A. W.; Barigou, M. 2009. Positron emission particle tracking (PEPT) compared to particle image velocimetry (PIV) for studying the flow generated by a pitched-blade turbine in single phase and multi-phase systems, Chemical Engineering Science 64: 4955-4968.

http://dx.doi. 10.1016/j.ces.2009. 08.003.

19. Ammar, M.; Driss, Z.; Chtourou, W.; Abid, M. S. 2012. Effect of the tank design on the flow pattern generated with a pitched blade turbine, International Journal of Mechanics and Applications 2(1): 12-19. http://dx.doi. 10.5923/j.mechanics.20120201.03.

20. Džiugys, A.; Navakas, R.; Šlančiauskas, A.; Stravinskas, G., Kačianauskas, R. 2005. Numerical simulation of mixing and segregation of granular material, Mechanika, 3(53): 52-56.
A. Belhanafi, M. Bouzit

NUMERICAL INVESTIGATION OF HYDRODYNAM-
ICS INDUCED BY A PITCHED BLADE TURBINE:
EFFECT OF THE SHAPE OF VESSEL BASE

S u m m a r y

This paper presents a numerical analysis influence of bottom shape on the hydrodynamic structure for cylindrical stirred vessel with bump. The turbulent flow generated in stirred tanks is numerically predicted by the resolution of the Navier-Stokes equation using standard k- $\varepsilon$ turbulent model. Several parameters on the mixture efficiency has been investigated. Particularly, we have studied the bottom shape of the tank, which is the distance between the bumpturbine with down pumping direction and impeller diameter. The numerical obtained results of the CFD (computational fluid dynamics) code CFX V13.0 with the MRF (Multi Reference Frame) are presented in order to understand the flow structure. The three components velocity profiles and the turbulent kinetic energy dimensionless distributions obtained at bottom tanks with three different heights are analyzed and discussed. From these results, we can confirm that including a bump at the bottom center of the tank closer to the turbine improves significantly the operating conditions of stirring and mixing. Predictions have been compared with literature data and a satisfactory agreement has been found.

Keywords: bottom shape, mixing, pitched bade turbine, tank height, turbulent flow.

Received March 23, 2019

Accepted October 14, 2019 